\title{
PWE-003 THE DEVELOPMENT OF A REPRODUCIBLE MODEL TO MEASURE CLINICAL PERFORMANCE IN AN ENDOSCOPY UNIT
}

doi:10.1136/gut.2011.239301.266

N Bullen, ${ }^{1, *}$ C Challand, ${ }^{2} \mathrm{~K} \mathrm{Hosie}^{1}{ }^{1} \mathrm{GI}$ directorate, Plymouth, UK; ${ }^{2}$ Derriford, Plymouth, UK

Introduction The Darzi Report states that seven steps are required to maintain and achieve high quality standards in the NHS including the measurement and publication of the quality of clinical performance. Clinical performance is a function of quality and cost-effectiveness in a tariff-based healthcare system. Reproducible models of performance may be helpful in developing quality improvement processes.

Methods Data from all endoscopy procedures performed within the main endoscopy unit at Derriford Hospital between January 2007 and December 2008 were analysed using the Endosoft database. Points were allocated as follows: two points per colonoscopy and one point for gastroscopy. A local health economic analysis revealed that $\geq 8$ points (or 4 colonoscopies) must be performed to meet costs. An interim analysis was performed and individualised feedback given to each endoscopist on their performance and possible areas for improvement. The audit cycle was completed over the next 12 months (2008) and then repeated over the subsequent 12 months (2009).

Results In total, 4371 colonoscopies were performed in 2009. (cf. 3884 in 2007, 4058 in 2008). There was an improvement in both crude Caecal Intubation Rate (CIR) from 89.6\% (2007) to $90.9 \%$ (2008 and 2009), and Points/List from 8.0 (2007) to 8.2 (2008) to 8.7 (2009). 'Clinical Performance' was compared by plotting a capability index of individual crude CIRs against Points/List. There is a shift towards increased quality being delivered in a cost effective way. The improvement in departmental Points/List equates to an increase in unit profitability greater than 500000 pounds.

Conclusion The introduction of auditable performance measurements has dramatically improved both the quality and productivity of our endoscopy unit. 
Competing interests None.

Keywords colonoscopy, outcomes, quality, safety, imaging, cancer, Cost effectiveness, performance.

\section{REFERENCE}

1. Department of Health (2008) High Quality Care For All: NHS Next Stage Review Final Report. The Stationary Office, UK. 